Editorial

\title{
Volume 4: Face-to-Face with SGAMR-2020 Awardees
}

\author{
${ }^{1}$ Chiara Bedon, ${ }^{2}$ Mario D'Aniello and ${ }^{3}$ Flavio Stochino \\ ${ }^{l}$ Department of Engineering and Architecture, University of Trieste, Trieste, Italy \\ ${ }^{2}$ Department of Structures for Engineering and Architecture, University of Napoli Federico II, Napoli, Italy \\ ${ }^{3}$ Department of Civil, Environmental and Architectural Engineering, University of Cagliari, Cagliari, Italy
}

...New Year and new results for the SGAMR community!!

The year 2021 begins with the announcement of Awardees for the first (ongoing) edition of SGAMR awards for Young Investigator (SGAMR-YRA-2020), Best Paper (SGAMR-BPA-2020) and Outstanding Reviewer (SGAMR-ORA-2020)!!

In this editorial, we want further to congratulate the Winners, but also present them to our Readers, Supporters, Authors, Reviewers as well as all Members of the editorial board. Therefore, we interviewed them in order to make their acquaintance and make known their research activity. The full list of questions for them is given as follows:

Q1) Please introduce yourself to the readers?

Q2) Can you talk about your current research topics and goals?

Q3) Going back in your research activity, would you like to change something?

Q4) What do you suggest to a Young Scientist?

Q5)As you know, SGAMR is an Open Access Journal. What do you think about $O A$ in the research community?

Q6) In these last months, day-life activities changed severely due to the pandemic. Do you think that glass will find even more use and space in the building sector, for new design concepts?

The presentation and interview of each Winners are reported hereinafter.

\section{Young Investigator Award (SGAMR-YRA- 2020)}

The Winner is Mr. David Kinsella, Ph.D. candidate at Lund University (Sweden), with his paper entitled "Using a Hierarchical Weibull Model to Predict Failure Strength of Different Glass Edge Profiles" (Kinsella and Lindström, 2020).

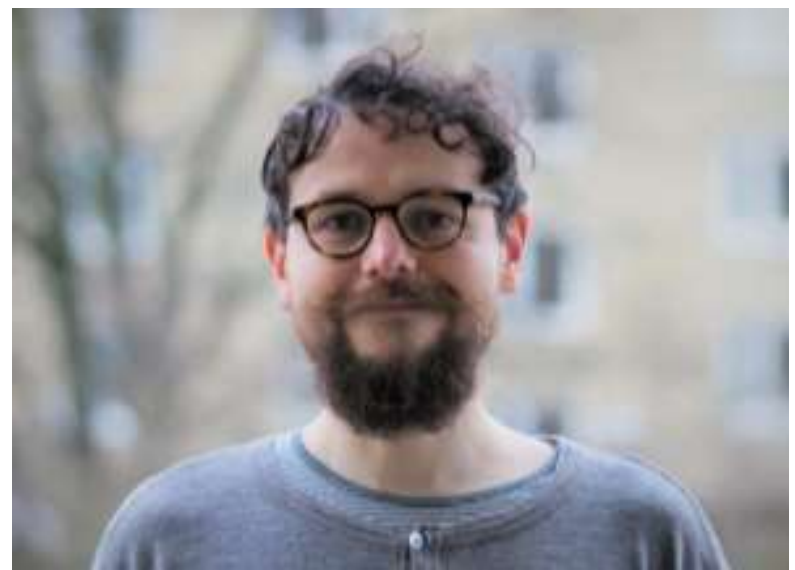

Mr. David Kinsella, winner of the Young Investigator Award (SGAMR-YRA-2020)

Q1) I am a final-year Ph.D. student at Lund University's Department of Construction Sciences, Sweden. I received a Master's degree in Structural Mechanics from Lund University and a Master's degree in Education from Malmö University, Sweden. Now I teach mechanics at the Construction Sciences Department of Lund University.

My recent publications include: "Using a Hierarchical Weibull Model to Predict Failure Strength of Different Glass Edge Profiles" (Kinsella and Lindström, 2020); "A Numerical Method for Analysis of Fracture Statistics of Glass and Simulations of a Double Ring Bending Test" (Kinsella and Persson, 2018); and "Performance of Standard Statistical Distributions for Modeling Glass Fracture" (Kinsella et al., 2018).

My current research interests are focused on numerical methods for modelling glass strength and fracture origins, including statistical aspects and experimental investigations. I previously served in the Research board at the Faculty of Engineering LTH, Lund University. When I am not writing about the strength of glass or reading glass engineering literature, I enjoy playing tennis and spending time with my family, which has seen the addition of a charming daughter since last year. 
Q2) I am currently completing a study on fracture modelling of glass plates in biaxial loading using numerical implementations of flaw-size based weakest-link systems. This includes experimental strength tests on glass plates subject to ring-on-ring and ball-on-ring loading with the goal to consider also surface area size effects.

Q3) Looking back, I think it would have been a good idea to plan and conduct some experimental tests at the beginning of the research project because there is a lot to be learned from this and the generated fracture data can be useful later on.

Q4) As a young scientist myself, I would suggest to other young scientists to be open to connect and network with other researchers in the glass engineering field which is a very international community.

Q5) Open Access makes a lot of sense. For example, a considerable part of the research funding in my own case comes from public grants which are supported by taxpayers who should not be charged twice to access the research results.

Q6) With the pandemic, many have started to carry out office work more from at home. However, our homes were not always designed with such purpose in mind. Access to natural light is important to our well-being, for example it is part of regulating our circadian rhythm. Glass will probably continue to find more use and space in the building sector with design concepts that address the needs and requirements of humans.

\section{Best Paper Award (SGAMR-BPA-2020)}

The Winner is Dr. Matthias Förch, now Director of Werner Sobek Hamburg (Germany), with his paper entitled "Time-Temperature Dependency of Laminated Glass Subjected to Blast Load-A Numerical Study" (Förch, 2020).

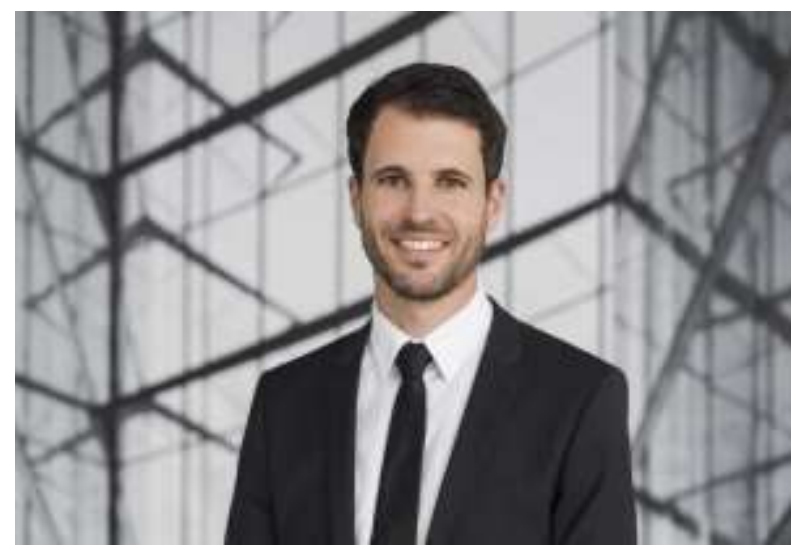

Dr. Matthias Förch, winner of the Best Paper Award (SGAMRBPA-2020)
Q1) I received my diploma degree in structural engineering from Biberach University of Applied Sciences (Germany) in 2005. After several years of practical experience as a structural engineer within the Permasteelisa Group and Nordex companies, I joined the working group for Façade Systems and Building Envelopes at HafenCity University Hamburg (Germany) as scientific assistant, from 2012 to 2018. During this period, I taught several courses for civil engineering and architectural engineering students in undergraduate and graduate studies. I have also published several papers and then received my Ph.D. degree on the Analysis of Glass Panels Subjected to Blast Load.

Successively, in 2019, I have joined the Werner Sobek group as Director of Hamburg office, where I am leading the team on unique projects in structural engineering and façade design. My research focus is on bomb blast protection of windows and facades and structural glass design.

Q2) In Germany, it is common for engineers to change between companies in free economy and research institutes, usually incorporated in public sector and vice versa. Since I have re-joined the private sector my research activity has reduced. However, as our exceptional projects often require innovative solutions in structural engineering, façade design and security engineering.

I have been involved in different remarkable research topics related to our projects at Werner Sobek. As these topics are usually linked to nondisclosure agreements, I am afraid of not being able to talk about them.

Q3) Unfortunately, I observe that science is drifting away from its fundamental idea in more and more scientific fields and countries around the world. Especially the financial situation of many research institutes has deteriorated in a way, that funding of research projects is only possible with the help of private economy and public sector being influenced by either private or political interests. In this context, I would appreciate notions to draw lines more clearly between research and funding.

Q4) Be passionate about your investigations and try to establish a focus and aim. Take your time, as solid research needs time to question, settle and understand background and context comprehensively. Document and present your results in a way that you will understand it in 10 years and always know that you know nothing.

Q5) Open Access Journals are a great format for a free and fast exchange of knowledge, as it is directly available for everybody around the world. In comparison to classical journals, the big advantage is that the audience is automatically extended from a 
privileged elite to everyone. Currently the downside of Open Access Journals is the relatively high publication fee that is charged to the authors. If authors did not allocate a publication budget in the beginning of their project or the budget is not granted, OA publication is not possible. I hope that the future will bring solutions to this disadvantage. One solution may be an international convention of research institutes, where each institute provides a publication budget due to a certain allocation key.

Q6) The pandemic may open eyes of some people in this regard. However, irrespective of the pandemic, I recognize in recent building designs that there is sometimes a lack of awareness of clients and even architects when it comes to natural light supply. Due to many various constraints during design processes of buildings the focus should not be allowed to fade away from initial purpose of buildings, that is mainly hosting occupants and providing comfortable environment for working and living. Here, natural light is a key aspect as we as human beings spend most of our lifetime inside buildings.

\section{Outstanding Reviewer Award (SGAMR- ORA-2020)}

The Winner is Prof. Fred Veer, from the Faculty of Architecture of Delft University of Technology (TU Delft, the Netherlands).

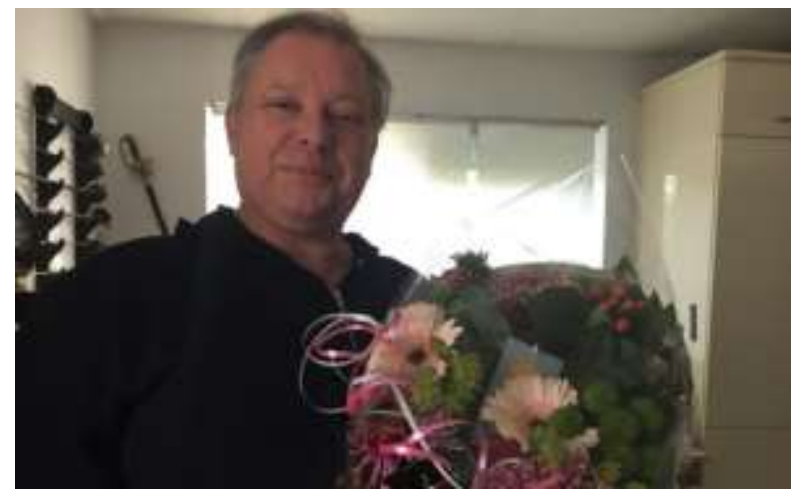

Prof. Fred Veer, winner of the Outstanding Reviewer Award (SGAMR-ORA-2020)

Q1) I studied materials science, did a Ph.D. on structural integrity and was appointed Assistant Professor in materials science at the Faculty of Architecture in 1994, then promoted to Associate Professor in 2007. I have studied the mechanical properties and fracture statistics of glass since 1995 and working on structural glass, I had/still have the opportunity to supervise Ph.D. students doing research on glass and sustainable structural design problems.
I specialize in experimental testing of glass and glass structures and digital microscopy and fractography. I teach general material science and specialized courses in materials selection and glass properties and design.

I am also a 5th dan Aikido teacher and love to spend the evenings teach Aikido.

Q2) I am busy with a study correlating glass defects after processing using advanced high resolution 3D digital microscopy with bending strength. The goals is to have a clear relation between glass processing and resulting glass edge strength in 5 years.

Q3) Not really. Even mistakes have been opportunities to learn valuable lesson.

Q4) Two things: First, only do a Ph.D. if you are passionate about the subject; secondly, there is no such thing as a failed experiment if you learn from failure.

Q5) Open access is the way to go. We do science for the sake of furthering science. That requires a free sharing of information and fast publication. This requires open access.

Q6) That is an interesting question. I would expect the long lock down to result in more open architecture, but the cost of the corona crisis will mean reduced budgets for buildings which will reduce innovation in structural glass.

\section{What's Next?}

The new call for the edition 2021 of SGAMR awards is open and we are waiting for you!

\section{References}

Förch, M. (2020). Time-Temperature Dependency of Laminated Glass Subjected to Blast Load-A Numerical Study. https://doi.org/10.1007/978-3662-59087-4_8

Kinsella, D. T., \& Persson, K. (2018). A numerical method for analysis of fracture statistics of glass and simulations of a double ring bending test. Glass Structures \& Engineering, 3(2), 139-152. https://doi.org/10.1007/s40940-018-0063-z

Kinsella, D., \& Lindström, J. (2020). Using a Hierarchical Weibull model to Predict Failure Strength of Different Glass Edge Profiles. International Journal of Structural Glass and Advanced Materials Research, 4, 130-148. https://doi.org/10.3844/sgamrsp.2020.130.148

Kinsella, D., Lindström, J., \& Persson, K. (2018). Performance of standard statistical distributions for modelling glass fracturee. International Journal of Structural Glass and Advanced Materials Research, 2, 178-190. https://doi.org/10.3844/sgamrsp.2018.178.190 